\title{
A Fully Implantable Epiretinal Vision Prosthesis for Retinitis Pigmentosa Patients
}

\author{
Thomas Schanze, Uwe Thomas \\ EpiRet GmbH \\ Winchester Straße 8 \\ D-35394 Gießen
}

\begin{abstract}
Retinal implants are an important approach to restore vision in patients that are blind due to photoreceptor loss from retinitis pigmentosa. There are two main approaches. One is the subretinal implant, which is implanted at the level of the degenerated photoreceptors. The second approach is the epiretinal implant, which is favourably placed on the inner retinal layer of an eye. In this, visual information is captured with an external camera, processed and transmitted to a retinal stimulator that is secured at the level of ganglion cells. As with most electrical prostheses advances are often related to advances in technology. Of equal importance are pre-clinic studies and surgical aspects of being able to implant such devices. Recently, the EpiRet group implanted and tested their epiretinal vision prothesis in blind subjects with retinitis pigmentosa. We present implant's design and results of a clinical study to demonstrate the applicability of the EpiRet vision prosthesis.
\end{abstract}

\section{Introduction}

Retinitis pigmentosa is a blinding disease in which retinal cells of the eye slowly and progressively degenerate. Postmortem analyses of retinitis pigmentosa patients have shown that a lot of retinal neurons, e.g. bipolar cells or ganglion cells, are retained compared to the light sensitive photoreceptor cells of the outer nuclear layer (Stone et al. 1992; Santos 1997). These remaining cells are functionally still intact and might be stimulated with electrical currents to restore vision (Eckmiller et al. 1994; Humayun 1996).

Retinal implants are an important approach to restore vision in patients that are blind due to photoreceptor degeneration. Two main approaches are under development (Rizzo and Wyatt 1997; Hesse et al. 2000; Zrenner 2002; Schanze et al. 2002, 2007; Humayun et al. 2003; Laube et al. 2005; Dowling 2005; Walter et al. 2005; Javaheri et al. 2006; Yanai et al. 2007; Mokwa 2007; Roessler et al. 2009). Subretinal implants are implanted between the pigment epithelial layer and the outer layer of the retina and try to stimulate the remaining intact retinal neurons - bipolar or horizontal cells, the initial neuronal processing stage of the retina - with electrical currents. Epiretinal implants have been designed to stimulate retinal ganglion cells - the final retinal processing stage - with an electrode array implanted onto the inner retinal membrane. In short, retinal implants stimulate retinal neurons electrically to restore a simplified visual image in the subject's brain.

The challenge of restoring vision is immense and progress is often related to advances in technology, which cross many scientific disciplines, from neurophysics to electrical engineering. Of equal importance are pre-clinic studies and surgical aspects of being able to implant such devices. Here, we report on a fully implantable epiretinal vision prosthesis. We describe its design, implantation and testing in blind volunteers with retinitis pigmentosa.

\section{Implant Design}

The notion of the EpiRet epiretinal implant approach is to affix an electrode array onto the retinal surface and to stimulate ganglion cells by adequate electric currents generated by an electronic device (Figure 1). This electronic device consists of a coil, a receiver and a stimulation chip. The implant can be wireless activated by an external transceiver which is also intended to assure an adequate data processing of visual scenes captured by a camera. 


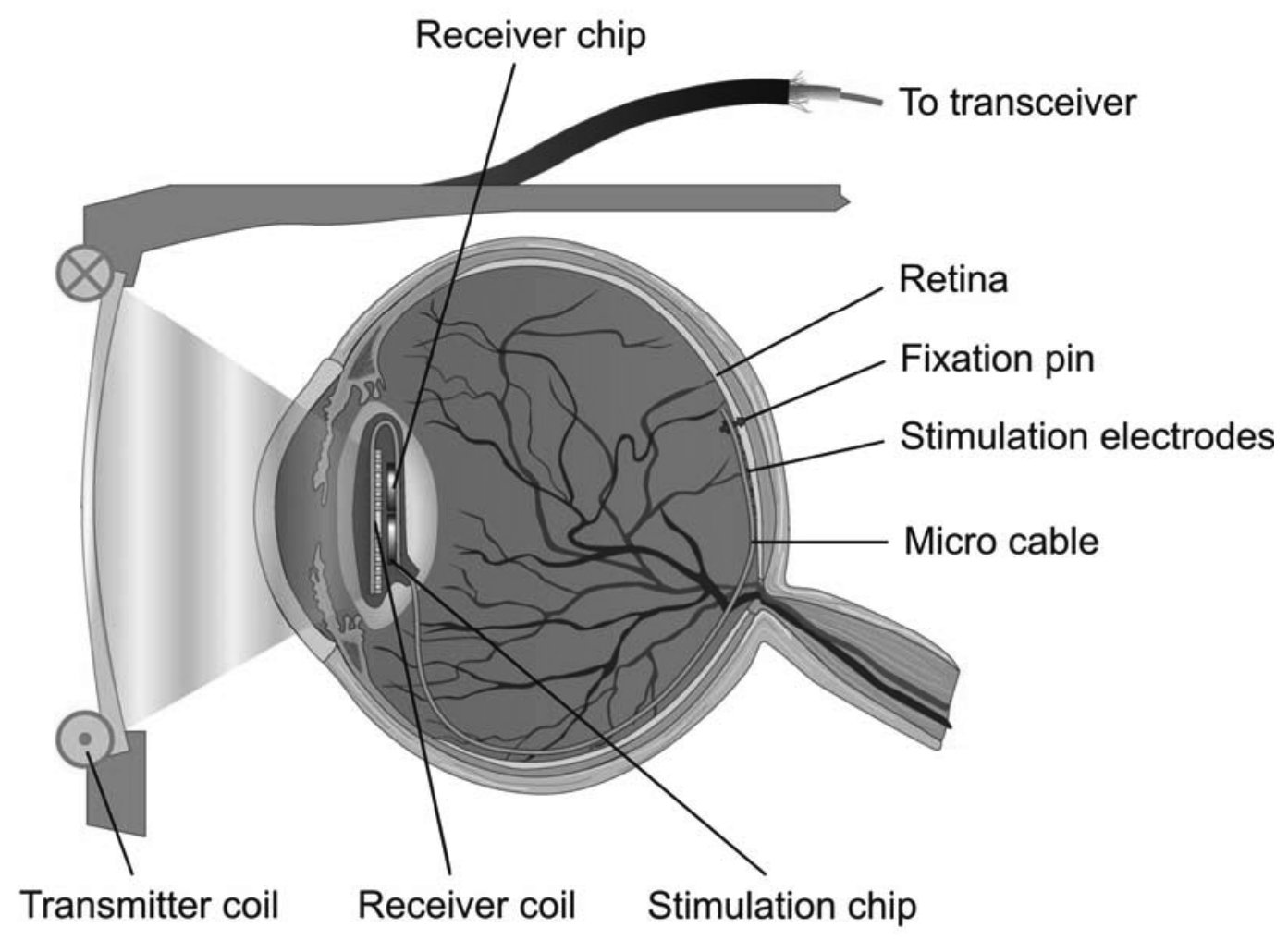

Figure 1. EpiRet retina implant system for vision restoration. Video camera captured visual information is processed by an external device (not shown) and, as energy, inductively transmitted to the intraocularly positioned receiver. After signal decoding the stimulation chip acitivates epiretinally placed electrodes for stimulation of remaining intact retinal neurons.

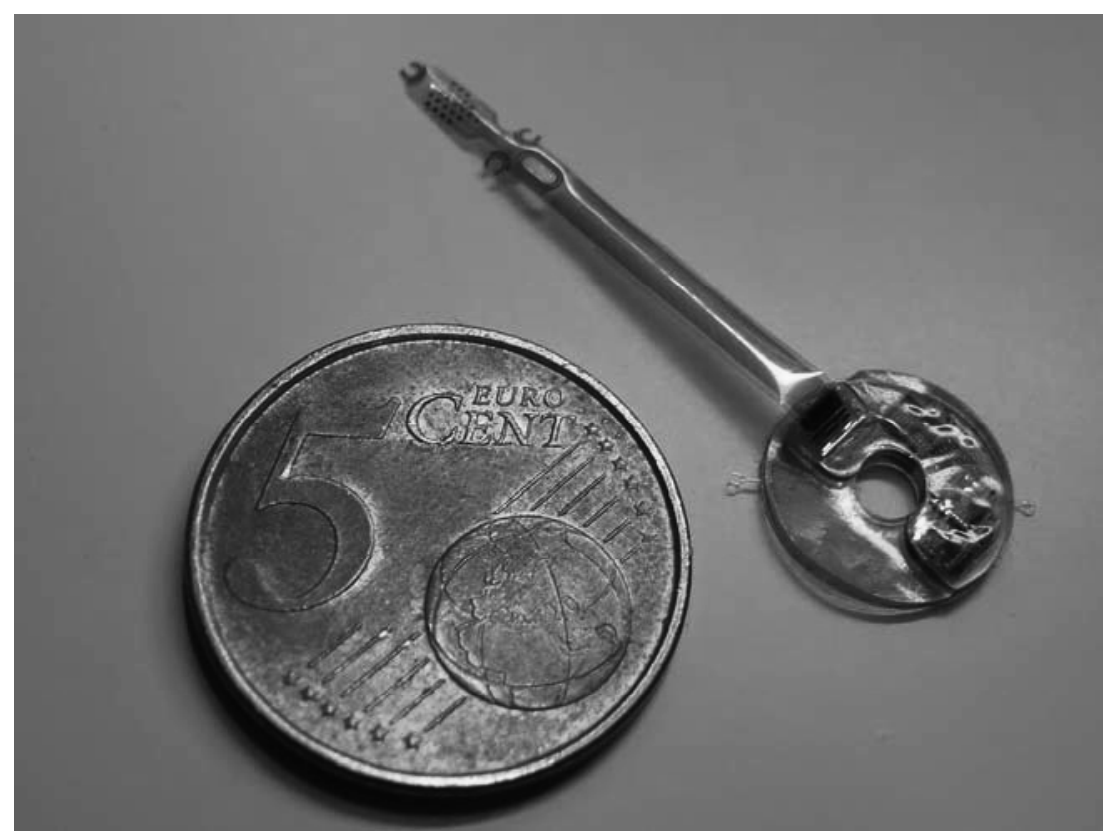

Figure 2. Fully implantable epiretinal retina implant. The implant can be telemetrically activated and has 25 electrodes (top side). Each iridium-oxide electrode has a threedimensional shape and was activated to ensure excellent stimulation impulse charge transfer. On the right side of the picture are the receiver coil and the electronics embedded in silicone rubber. Note the picots required for thread-fixation in the eye's lens-capsule. The five-cent coin serves as a ruler. 


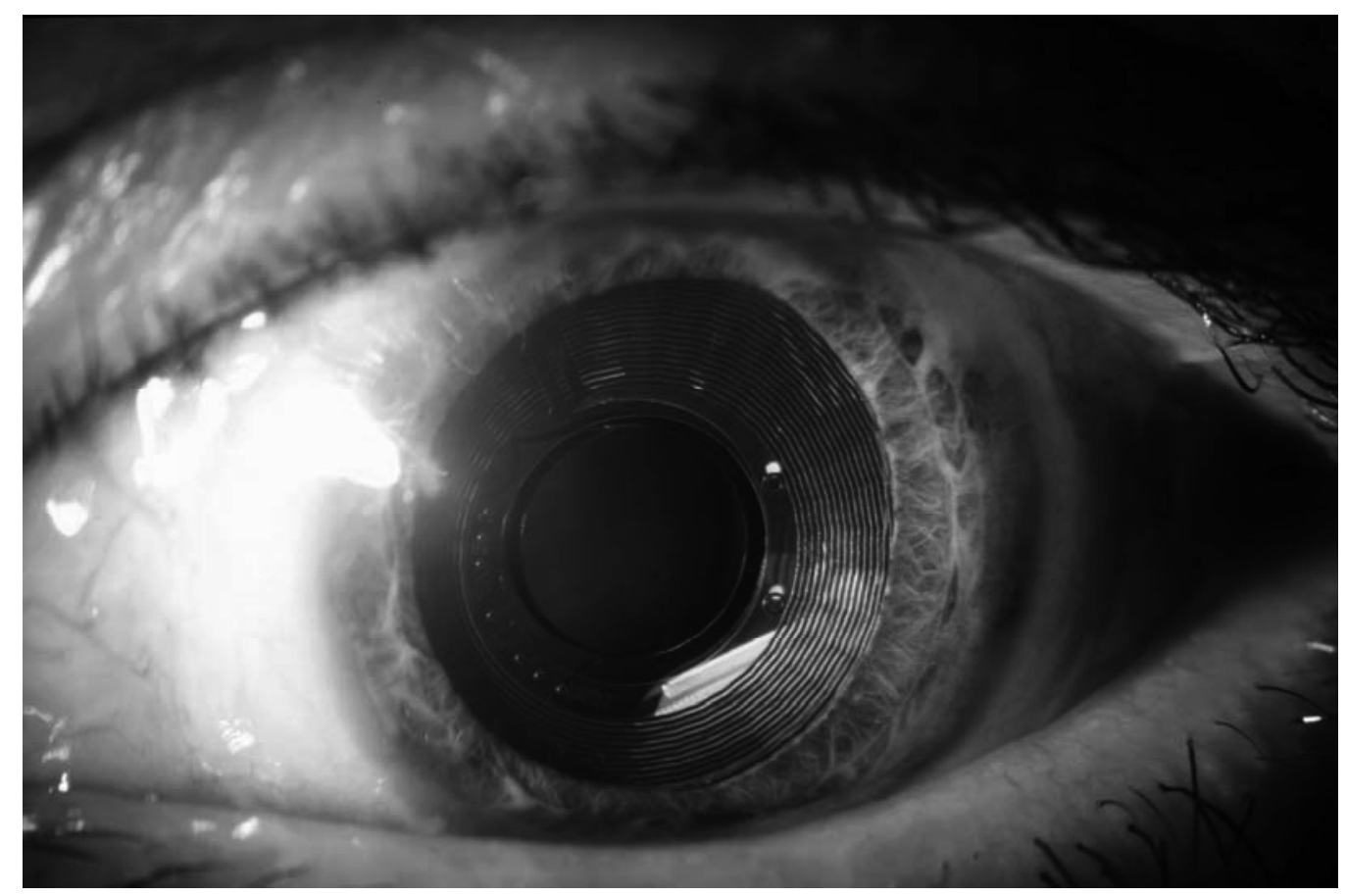

Figure 3. Implanted epiretinal retina implant.

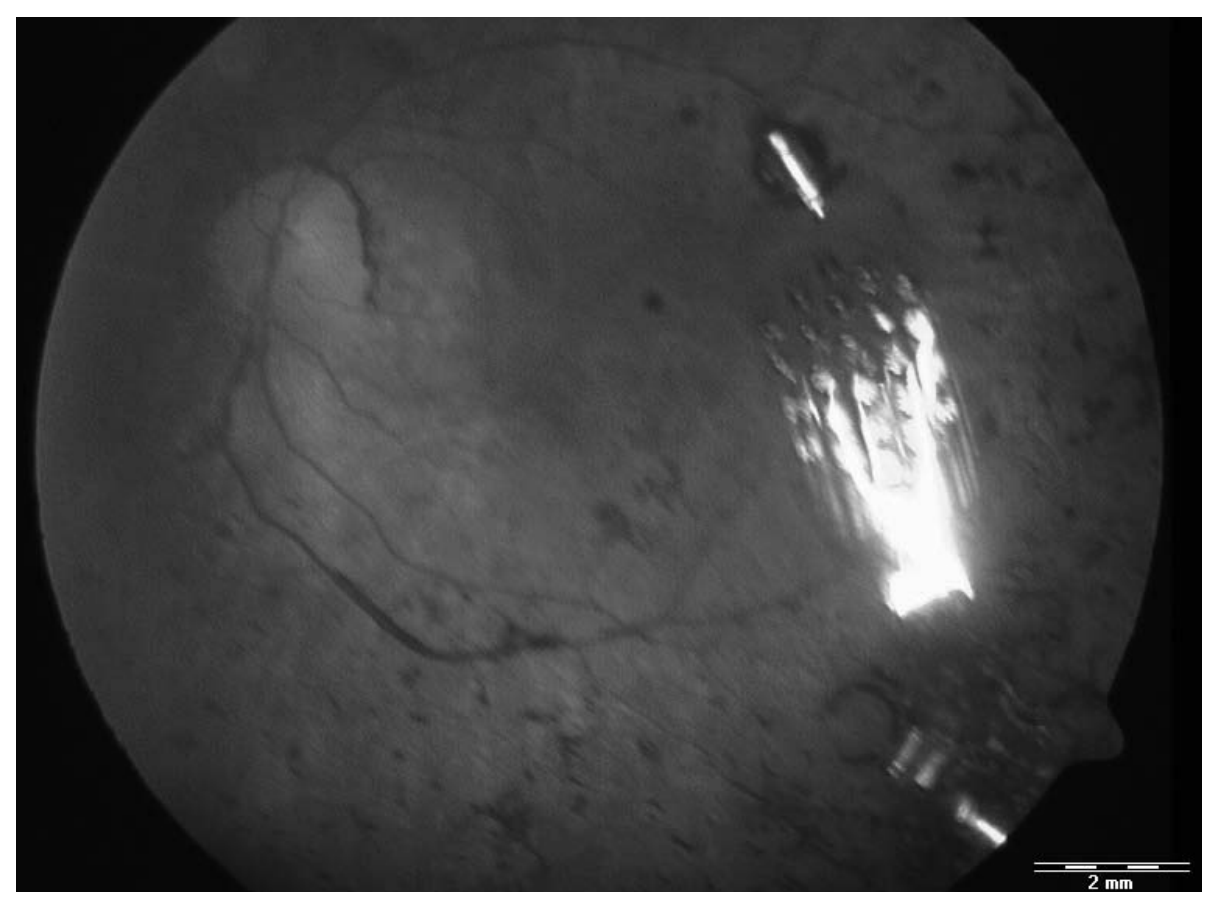

Figure 4. Fundus photography of the epiretinal implant's electrode array. The stimulation electrode array was secured safely with a modified retinal fixation pin on the central area of retinal surface; the optic disk is in the upper left quadrant. This approach establishes an intimate electrical contact between electrode and ganglion cells as required for successful low-threshold stimulation. The dark retinal spots are due to retinitis pigmentosa. 
The materials for electrodes and for supporting and housing of the electronic chips have to fulfil a variety of tasks. They have to be highly flexible, smooth, stable, light-weighted, robust, easily implantable and biocompatible. In addition, the printed circuit board has to connect the chips and has to be a base for the electrodes.

We selected polyimide as a basic substrate and housing material for the conductors, the metallic contact pads, the micro cable, the electrode array and the galvanically deposited high-Q receiver coil. Electronic circuits were protected by Parylene $C$ and by silicone rubber. Form and shape of the silicone rubber is like that of an intraocular lens as required for safe implantation. A crucial point for low-threshold and high resolution and information transfer stimulation is the electrode design (Schanze et al. 2002, 2003, 2006, 2007; Eger 2005; Eckhorn et al. 2006; Eckhorn 2007). Raised or three-dimensional electrodes prospect superior stimulation results compared to flat electrodes. Thus we designed three-dimensional electrodes. The contact area of a three-dimensional electrode consists of sputtered and activated iridium-oxide. This ensures a high charge delivery capacity as required for safe and local low threshold stimulation. More details concerning principles of wafer-level production processes, assembly and packaging, and electrode design are given elsewhere (Stieglitz et al. 2000; Mokwa 2004, 2007; Hungar et al. 2005; Mokwa et al. 2008). Implant materials and implants were, of course, tested to be biostable and biocompatible (Schanze et al. 2007; Sellhaus et al. 2008).

\section{Clinical Study}

A clinical study was designed and approved by local governments for implantations and implant testing at the Departments for Ophthalmology at RWTH Aachen University and University Essen. Eight blind volunteers suffering from retinitis pigmentosa received the EpiRet implant (Figures 2, 3, and 4). All implantations were successful and after four weeks the implants were explanted. Retinal stimulation and recording of the volunteers' perceptions proofed that vision can be restored with a fully implantable epiretinal vision prosthesis. The volunteers clearly reported visual sensations evoked by electrical stimulation. These phosphenes were related to stimulation parameters like stimulation current's amplitude and the duration of the biphasic charge-balanced current impulses. In correspondence with preceding animal studies (e.g. Schanze et al. 2002; 2003) we demonstrated for the first time ever that low threshold stimulation $\left(<10 \mu \mathrm{A},<10 \mu \mathrm{C} / \mathrm{cm}^{2}\right)$ is feasible in patients with degenerated retinae. The perception of electrical stimulation was tested over four weeks and showed that important stimulation parameters like threshold, orientation, form, contrast and colour of basic visual objects as well as stimulation resolution and stability can be assessed and optimized.

\section{Discussion and Conclusions}

The major result of this paper is that with retinal implants restoring of vision in patients with retinitis pigmentosa is feasible. However, it had taken an interdisciplinary approach and more than 15 years to proof this. Pre-clinical trials were necessary and important for verification of design, implantation procedures and proof of principle. The clinical trials yielded important knowledge about retinal implant evoked visual sensations/perceptions. These results are the basis to solve the upcoming challenge: the intelligent epiretinal implant with adaptive high quality information processing of visual scenes as a medical product to restore vision in blind subjects with retinitis pigmentosa.

\section{Acknowledgements}

The authors gratefully acknowledge their association with the German Retina Implant EPIRET Group. Supported by the German Federal Ministry of Education, Science, Research, and Technology, BMBF. 
Picture credits (@). Fig. 1: RWTH Aachen, IWE I, 2008; modified. Fig. 2: EpiRet GmbH, 2008. Fig. 3. University Essen, Dept. Ophthalmology, 2008; modified. Fig. 4: RWTH Aachen, Rössler et al., 2009; modified.

\section{References}

Dowling J (2005) Artifical human vision. Expert Rev Med Devices 1, 73-85

Eckhorn R, Wilms M, Schanze T, Eger M, Hesse L, Eysel UT, Kisvárday ZF, Zrenner E, Gekeler F, Schwahn H, Shinoda K, Sachs H, Walter P (2006) Visual resolution with retinal implants estimated from recordings in cat visual cortex. Vision Res 46, 2675-2690

Eckhorn R (2007) Spatial, temporal-, and contrast resolutions obtainable with retina implants. Ophthal Res: Visual Prosthesis and Ophthalomic Devices: New Hope in Sight. Ed: Tombran-Tink J, Barnstable C, Rizzo JF, Humana Press Inc., Totowa, NJ

Eckmiller R / Joswig M / Napp-Zinn H / Kreimeier B, Eckhorn R / Schanze T, Ehrfeld W / Schulz C, Gersonde K / Meyer J-U, Heuberger A / Wagner B, Hömberg V / Daunicht WJ, Hostika B / Schwarz M, Jäger D / Buß R, Klar H / Jahnke A, Linke D, Noth J, Samii / Penkert G, Zimmer G / Mokwa W (1994) Neurotechnologie-Report I: Machbarkeitsstudie und Leitprojekt-Vorschlag. Herausgeber: Bundesministerium für Forschung und Technologie, Bonn, April 1994

Eger M, Wilms M, Eckhorn R, Schanze Th, Hesse L (2005) Retino-cortical information transmission achievable with a retina implant. BioSystems 79, 133-142

Hesse L, Schanze Th, Wilms M, Eger M (2000) Implantation of retina stimulation electrodes and recording of electrical stimulation responses in the visual cortex of the cat. Graefe's Arch Clin Exp Ophthalmol 238, 840-845

Hungar K, Görtz M, Slavcheva E, Spanier G, Weidig C, Mokwa W (2005) Production processes for a flexible retina implant. Sensors and Actuators A: Physical 123-124, 23 September 2005, 172-178. Eurosensors XVIII 2004 - The 18th European conference on Solid-State Transducers.

Humayun MS, de Juan E, Dagnelie G, Greenberg RJ, Propst RH, Phillips DH (1996) Visual perception elicited by electrical stimulation of retina in blind humans. Arch Ophthalmol 114, 40-46

Humayun MS, Weiland JD, Fujii GY, Greenberg R, Williamson R, Little J, Mech B, Cimmarusti V, Van Boemel G, Dagnelie G, de Juan E Jr (2003) Visual perception in a blind subject with a chronic microelectronic retinal prosthesis. Vision Res 43, 2573-2581

Javaheri, MJ, Hahn DS, Lakhanpal RR, Weiland JD, Mark S Humayun MS (2006) Retinal prostheses for the blind. Ann Acad Med Singapore 35, 137-144

Laube T, Akguel H, Schanze T, Goertz M, Bolle I, Brockmann C, Bornfeld N (2004) First time successful epiretinal stimulation with active wireless retinal implants in Göttinger minipigs. Invest Ophthalmol Vis Sci 45, 4188.

Mokwa W (2004) MEMs technologies for epiretinal stimulation of the retina. J Micromechanics and Microengineering 14 S12-S16

Mokwa W (2007) Medical implants based on microsystems. Meas Sci Technol 18, R47-R57

Mokwa W, Görtz M, Koch C, Krisch I, Trieu H-K, Walter P (2008) Intraocular epiretinal prothesis to restore vision in blind humans. Proc. of the $30^{\text {th }}$ Annual International Conference of the IEEE Engineering in Medicine and Biology Society, Vancouver, 5790-5793

Rizzo JF, Wyatt JL (1997) Prospects for a visual prosthesis. The Neuroscientist 3, 251-262 
Roessler G, Laube T, Brockmann T, Kirschkamp T, Mazinani B, Goertz M, Koch C, Krisch I, Sellhaus B, Trieu HC, Weis J, Bornfeld N, Röthgen H, Messner A, Mokwa W, Walter P (2009) Implantation and explantation of a wireless epiretinal retina implant in blind RP patients. IOVS, in press

Santos A, Humayun MS, de Juan E, Greenberg R, Marsh MJ, Milam AH (1997) Inner retinal preservation in retinitis pigmentosa: a morphometric analysis. Arch Ophthalmol 115, 511-515

Sellhaus B, Schanze T, EPI RET 3 Group (2008) The EPI RET3 Wireless intraocular retina implant system: Biocompatibility of the EPI RET 3 device. ARVO Conference, Fort Lauterdale, 3009/D605

Schanze T, Wilms M, Eger M, Hesse L, Eckhorn R (2002) Activation zones in cat visual cortex evoked by electrical retina stimulation. Graefe's Arch Clin Exp Ophthalmol 240, 947-954

Schanze Th, Greve N, Hesse L (2003) Towards the cortical representation of form and motion stimuli generated by a retina implant. Graefe's Arch Clin Exp Ophthalmol 241, 685-693

Schanze T, Sachs HG, Wiesenack C, Brunner U, Sailer H (2006) Implantation and testing of subretinal film electrodes in domestic pigs. Exp Eye Res 82, 332-340

Schanze T, Hesse L, Lau C, Greve N, Haberer W, Kammer S, Doerge T, Rentzos A, Stieglitz T (2007) An optically powered single-channel stimulation implant as test system for chronic biocompatibility and biostability of miniaturized retinal vision prostheses. IEEE-TBME 54, 983-992

Stieglitz T, Keller R, Beutel H, Meyer J-U (2000) Microsystem integration techniques for intraocular vision prostheses using flexible polyimide-foils. Proceedings of the MICRO.tec 2000, 25-27 September 2000, Hannover/Germany, 467-472

Stone JL, Barlow WE, Humayun MS, de Juan E, Milam AH (1992) Morphometric analysis of macular photoreceptors and ganglion cells in retinas with retinitis pigmentosa. Arch Ophthalmol 110, 16341639

Walter P, Kisvárday ZF, Görtz M, Alteheld N, Rössler G, Stieglitz T, Eysel UT (2005) Cortical activation with a completely implanted wireless retinal prosthesis. Invest Ophthalmol Vis Sci 46, 1780-1785

Yanai D, Weiland JD, Mahadevappa M, Greenberg RJ, Fine I, Humayun MS (2007) Visual performance using a retinal prosthesis in three subjects with retinitis pigmentosa. Am J Ophthalmol 143, 820-827

Zrenner E (2002) Will retinal implants restore vision? Science 295, 1022-1025 